$114-115$

Debate

e Investigación

Sedes web

PH42 - Febrero 2003

\title{
Sedes web
}

\section{Desarrollo local y patrimonio en Internet}

La presencia del desarrollo local y sostenible dentro de la Web es desde hace unos años muy amplio y variado, dada la conciencia que los distintos gobiernos y autoridades locales de los distintos países están tomando sobre la necesidad de invertir recursos en la gestión y el impulso cultural, económico y social de las regiones y, en concreto, de los municipios.

A nivel mundial, existen distintos Comités, Consejos, Federaciones y Redes, cuyo fin es favorecer e impulsar los entornos rurales y urbanos, el intercambio entre los pueblos, cooperación internacional y el desarrollo sostenible, además de promover y divulgar diversas actividades, cumbres, jornadas y seminarios para establecer políticas globales de actuación.

De todos ellos, existe una amplia representación en Internet de entre los que hemos seleccionado algunos ejemplos que abarcan desde una perspectiva mundial, descendiendo hasta el territorio nacional, y ya más en concreto, el andaluz.

Comenzando por los organismos internacionales, podemos destacar las siguientes sedes ${ }^{1}$ :

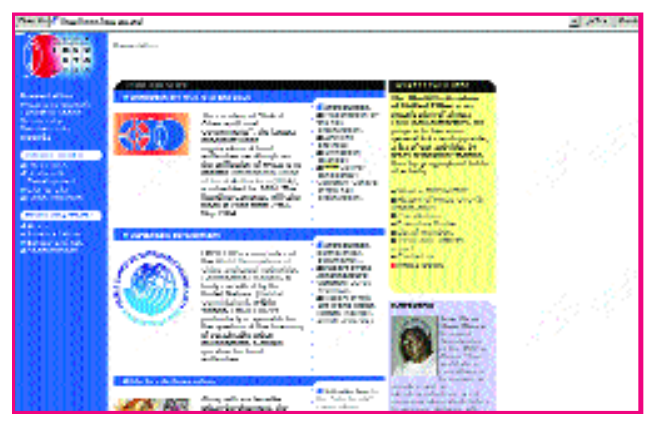

Federación Mundial de las Ciudades Unidas (FMCU): http://www.fmcu-uto.org/; como casi todas las sedes Web que tratan temas donde entra en juego el factor político unido al deseo de proporcionar información clara y directa para llamar a la adhesión a un determinado proyecto de envergadura, se presenta como un portal dinámico con múltiples secciones muy compartimentadas. A pesar de todo, la navegación es sencilla con un índice fijo a la izquierda que presenta las secciones principales y sus contenidos estructurados en forma de árbol, con los siguientes temas: Presentación, dentro de la que destaca una Agen- da de eventos de gobiernos locales y sus asociaciones, así como un formulario en línea de demanda de adhesión, abierto a todo gobierno local o regional. También aparece el documento de la constitución de la Federación en mayo de 2001.

Dentro de la sección de temas generales, cabe destacar la unión de la FMCU con la Unión Internacional de Gobiernos y Autoridades locales (IULA), y el apartado City-to-City, basado en la política de hermanamientos y relaciones entre autoridades locales.

Además, se presenta el amplio marco geográfico donde la federación desarrolla sus actividades, dentro de Africa, América latina, Europa y el Mediterráneo.

En definitiva, la Web presenta una navegación ágil y práctica, donde prima el contenido sobre el diseño. En todas las secciones figura un recuadro en amarillo donde se nos advierte a modo de sumario sobre los contenidos, con numerosos links a otras informaciones de interés. La dirección Web se muestra en el logotipo y el idioma empleado es el inglés y el francés, aunque existen algunos documentos descargables en otros idiomas, como una Circular periódica de la propia federación que la encontramos en español, donde se anuncia una nueva organización de autoridades locales que tendrá lugar en Barcelona en mayo de 2004.

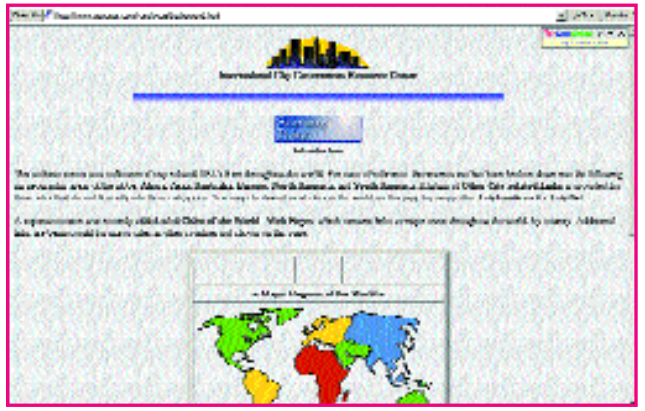

En segundo lugar, destacamos la sede del Centro Internacional de Recursos de los Gobiernos de Ciudades: http://www.geocities.com/Paris/9925/, página que actúa como un directorio o banco de enlaces clasificados por continentes y regiones y dentro, por paises. Es destacable por su carácter consultivo y aglutinador de recursos útiles sobre la ma- 


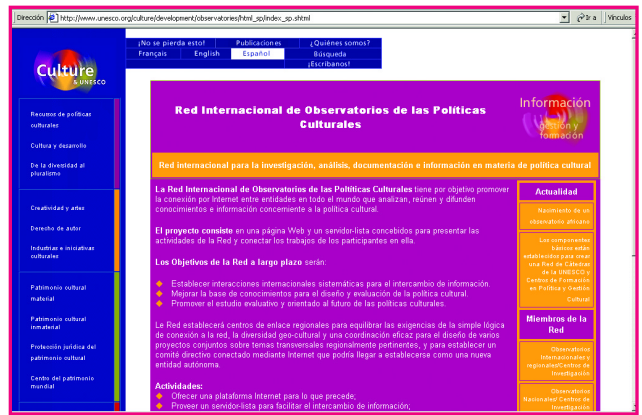

Existen también redes internacionales como la que nos muestra la Sección de Cultura de la UNESCO: http://www.unesco.org/culture/ development/observatories/html_sp/index_sp.shtml, a través de sus observatorios de políticas culturales, donde, empleando esta vez colores más cálidos, encontramos un índice con varias secciones entre las que destacan: Recursos de políticas culturales, Cultura y desarrollo, Patrimonio cultural material e inmaterial y Protección jurídica del patrimonio cultural.

Además, se muestran quiénes son los miembros de la red y se oferta un servicio de lista-e para dichos miembros. La información la podemos encontrar en inglés, francés y español.

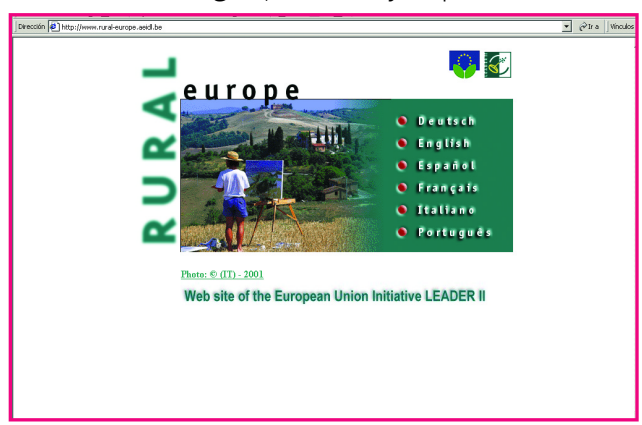

Descendiendo a nivel europeo, encontramos la sede Web del programa europeo LEADER II de desarrollo rural: http://www.rural-europe.aeidl. be/, donde podemos encontrar en seis idiomas distintos, entre ellos el español, bases de datos sobre grupos de acción local, proyectos de cooperación, unidades nacionales y administraciones nacionales y regionales, entre otros. Además, en el cuerpo central de la página encontramos una guía pedagógica del planteamiento LEADER, un boletín mensual, la revista LEADER y un foro sobre evaluación de las distintas necesidades que pueden presentar los territorios y grupos de acción local.

En la parte superior de la página, encontramos también cuatro botones horizontales que nos dan acceso a: Biblioteca, con artículos sobre temas tan variados como la Cultura, la Formación, la Investigación, el Medio Ambiente, los Servicios en el medio rural o las Políticas de desarrollo rural; Medidas Comunitarias, con un amplio abanico de programas europeos que pueden interesar a los agentes rurales, tales como la Política Cultural (Cultura 2000), Política de Medio Ambiente, Política Social, o Política Agrícola y Desarrollo Rural.
En definitiva, y al igual que en los casos anteriores, la navegación es ordenada y limpia y el diseño está dirigido con sencillez, siguiendo la tónica de la mayoría de las páginas Web de politicas comunitarias.

Centrándonos en el ámbito nacional y regional, hemos elegido tres sedes representativas: La Red Española de Desarrollo Rural, La Federación Andaluza de Municipios y Provincias y La Asociación para el Desarrollo Rural de Andalucía.

La sede Web de la Red Española de Desarrollo Rural: http://www.redr.es, ofrece servicios de interés como la posibilidad de anexionarse al Anillo español de desarrollo local o de suscribirse a la lista de correo de la red. Asimismo, existe una zona de socios, un lugar para la Agenda y enlaces de interés sobre el tema, así como un directorio de grupos de acción local. Es una asociación sin ánimo de lucro integrada por 164 grupos de acción local que promueve el desarrollo rural, con el fin de agrupar, aprovechar y compartir los recursos de los distintos territorios gestionados. Todo ello bajo el prisma del programa europeo LEADER y el programa nacional PRODER.

La Web está en español y cuenta con un buscador y un mapa del Web. Tiene un diseño sencillo y ordenado y en la navegación no perdemos en ningún caso la referencia obligada al índice gene-

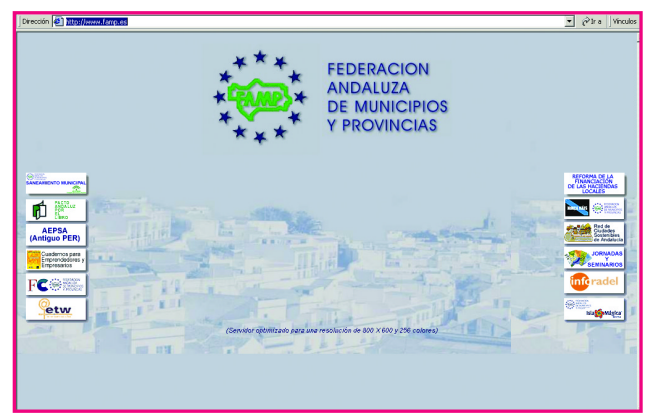

ral.

Ya dentro del marco regional destacamos en primer lugar la sede de la Federación Andaluza de Municipios y Provincias: http://www.famp. es/, en la que lo más destacado son las secciones dedicadas a las Jornadas y Seminarios, donde encontramos un amplio listado de congresos y seminarios dedicados a temas tan variados como ciudades saludables, gestión del patrimonio documental, municipios turísticos sostenibles, cultura y municipio, gestión del patrimonio local, etc., y la sección dedicada a las redes de la FAMP, entre las que cabe resaltar la RADEL (Red Andaluza de Desarrollo Local). La página cuenta con información sobre sus normas de organización, el plan de trabajo, criterios de adscripción y cuotas de los socios.

La estructura y navegación por la sede es clara y bien resuelta en todos los niveles, utilizando colores suaves que invitan a fijar más la atención sobre la información que se ofrece. Ade- 


\section{$116-117$ \\ Debate e Investigación \\ Sedes web \\ PH42 - Febrero 2003}

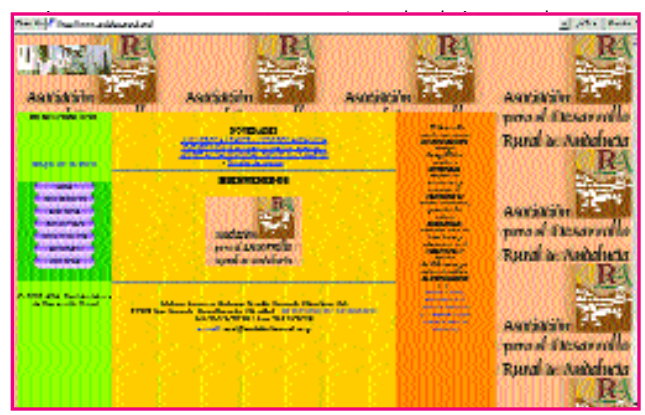

Finalmente, la sede del la Asociación para el Desarrollo Rural de Andalucía:

http://www.andaluciarural.org/, es una web de obligada consulta para todo lo que afecta a desequilibrios sociales y territoriales, mejora de las estructuras y promoción del nacimiento de nuevas actividades, potenciación de los sectores tradicionales, etc. Es una página muy completa con una amplia oferta de servicios, pudiendo acceder a una biblioteca de artículos especializados, participar en foros y chats, obtener la revista Tierra Sur en formato electrónico, conocer las ayudas y subvenciones de la administración y consultar diariamente las noticias relacionadas con el sector y, por otro lado, las aparecidas en la prensa.

También cuenta con un apartado para los Miembros y una sección de Enlaces a Grupos de Desarrollo Andaluces y Redes Regionales españolas, así como a las distintas iniciativas europeas.

En cuanto al diseño hay un cierto exceso y variedad de color en las páginas, aunque el indice principal está presente en todos los niveles como hilo conductor. Hay una considerable representación gráfica en comparación con las anteriores sedes analizadas, lo cual otorga imagen a la información reflejada y favorece la comprensión del contenido, contribuyendo además a una navegación más atractiva.

Finalmente, no queremos olvidar el papel que juegan dentro de toda esta política de desarrollo los Centros de Interpretación del Patrimonio como estrategia de impulso territorial. Para ello, destacaremos algunos elementos útiles encontrados en relación con este tema dentro de algunas sedes relevantes:

En primer lugar, destacamos la Ciudad Virtual de Antropología y Arqueología (el portal de Antropología en español): http://www.naya.org.ar/ turismo/congreso/ponencias/margalida_castells.ht, donde encontramos un interesante artículo sobre este tema. Además, la interpretación del patrimonio es tratada por la empresa aragonesa PRAMES, la cual ha creado un centro de interpretación en Huesca, mostrando su experiencia en su sede Web: http://www.prames. com/patrimonio.html, así como la empresa catalana Dinamització del Patrimoni, empresa de servicios de información pedagógica, histórica, cultural, y de dinamización de monumentos, conjuntos históricos, museos y patrimonio industrial: http://www.ber gueda.net/dinapat/indexcastella.htm.

No obstante, es la Asociación Española de Gestores del Patrimonio Cultural (AEGPC), http: //www.aegpc.org/beta2/BETA2/, cuyo objetivo principal se basa en colaborar en la conservación, difusión y engrandecimiento del Patrimonio Cultural del Estado Español fomentando la gestión del mismo con criterios profesionales, y, fomentando su aprovechamiento social como recurso, tanto económico como cultural, la que ofrece una más amplia información en Internet en el ámbito de la gestión del patrimonio cultural, con una sección de enlaces y actividades entre sus contenidos más relevantes. Además, cuenta con dos publicaciones periódicas de amplio contenido: Areté Digital como boletín electrónico mensual de la Asociación, y el boletín digital de la REDIPAC (Red Iberoamericana del Patrimonio Cultural) http://www.aegpc.org/Redipac. htm, de gran inter és por el número de convocatorias y jornadas recopiladas en el mismo.

Finalmente, de los contenidos más relevantes aparecidos en la publicación Areté, tenemos que destacar los boletines de interpretación del patrimonio en formato electrónico de la Asociación para la Interpretación del Patrimonio (AIP E $\quad s \quad p \quad$ a $\quad \tilde{n}$ a l : http://www.interpretaciondelpatrimonio.com/ pdf/boletin-7.pdf.

En definitiva, y como conclusión, la proliferación de asociaciones, comités, federaciones y otras organizaciones, en todos los ámbitos geográficos, tanto mundiales como regionales, preocupados por el desarrollo local, rural y urbano, así como la Comunidad Europea que apuesta e invierte en ello, creando iniciativas y programas para favorecer las distintas políticas implicadas (agrícolas, culturales, sociales, económicas, etc.), reflejan todo su potencial en la Red, dándose a conocer a través de páginas repletas de información, ofreciendo diversos servicios útiles para la adhesión a redes internacionales y locales.

Internet es utilizado en este ámbito como una herramienta de divulgación de información y de trabajo. La importancia del diseño es secundaria, aunque se logra un equilibrio entre la calidad y la cantidad de la información, sin restarle a las páginas rigor y profesionalidad. No se trata de vender un producto de forma atractiva y novedosa, sino de crear un circuito de comunicación entre todos los interesados en el desarrollo y la

\section{Susana Limón Rodríguez}

Centro de Documentación del IAPH

interpretación del patrimonio, útil para la puesta en marcha de las políticas pertinentes. 